\title{
Development of a Method to Detect Viral RNA Sequences From Cultured Cells by Combining Size Fraction and a Rapid Determination System for Viral RNA Sequences (RDV)
}

Shumpei Watanabe ${ }^{1}$, Tetsuya Mizutani ${ }^{2 *}$, Kouji Sakai ${ }^{3}$, Itoe lizuka², Tomoyuki Shiota², Yusuke Sayama ${ }^{2}$, Shumpei Tsuda1, Kentaro Kato', Shuetsu Fukushi², Masayuki Saijo², Ichiro Kurane ${ }^{2}$, Shigeru Morikawa ${ }^{2}$ and Hiroomi Akashi ${ }^{1}$

${ }^{1}$ Department of Veterinary Microbiology, Graduate School of Agricultural and Life Sciences, University of Tokyo, 1-1-1 Yayoi, Bunkyo-ku, Tokyo 113-8657, Japan

${ }^{2}$ Department of Virology 1, National Institute of Infectious Diseases, Gakuen 4-7-1, Musashimurayama, Tokyo 208-0011, Japan

${ }^{3}$ Division of Experimental Animals Research, National Institute of Infectious Diseases, Gakuen 4-7-1, Musashimurayama, Tokyo 208-0011, Japan

\begin{abstract}
By combining size-fraction and a rapid determination system for viral RNA sequences (RDV), a method for sequence independent detection from virus-infected cultured cells was developed as "RDV-size fraction (RDV-SF)". Using RDVSF, we succeeded in detecting nucleotide fragment sequences of feline calicivirus (FCV) and Yokose virus (YOKV) from Vero E6 cells infected with FCV and YOKV, respectively. RDV-SF was useful in identifying RNA viruses with a genome size of more than $5 \mathrm{~kb}$ from virus-infected cultured cells.
\end{abstract}

Keywords: Direct sequencing; RDV-SF; RNA virus; Sequenceindependent detection

Emerging viruses continue to surprise us, providing many newly recognized diseases to study and to try to control. Early discovery of infectious viruses is necessary to prevent potential outbreaks. Virus discovery has been aided by the development of sequenceindependent methods for obtaining genomic data. The most prominent of these methods include representational difference analysis (RDA) and sequence-independent single primer amplification (SISPA) with several variations [1-3,5,7,10-11]. However, the sensitivity of the RDA method is inadequate for virus detection. In addition, these methods including RDA or SISPA comprise a cloning step. For cloning, a DNA amplicon is inserted into the plasmid to determine the nucleotide sequence after sequence-independent amplification. However, cloning requires longer experimental time compared to direct sequencing. Recently, we developed a new method for sequence-independent detection of RNA viruses using direct sequencing, i.e., a rapid determination system for viral RNA sequences (RDV) . Using RDV and improved RDV, several novel viruses have been discovered and identified until now $[4,6,8-9,12,13]$. Thus, the RDV method is a powerful tool for identification of unknown viruses. However, materials for the method are limited to cell culture supernatants or liquid samples such as serum, because the cellular nucleic acids interrupt detection of the viral genome. Therefore, in the present study using the RDV method, we attempted to develope a new sequence-independent method for detecting RNA viruses from cultured cells.

A method combining size fraction and the RDV method (called RDV-SF) was designed using extracted RNA from feline calicivirus (FCV)-infected Vero E6 cells. The size fraction method is summarized in Figure 1. The F4 strain of FCV was infected to Vero E6 cells at a multiplicity of $1 \mathrm{TCID}_{50} /$ cell. At $16 \mathrm{~h}$ post infection, virus-infected cells were harvested. Viral RNA was extracted using a total RNA isolation mini kit (Agilent Technology, USA) according to the manufacturer's instructions, and eluted in $50 \mu \mathrm{l}$ of RNase-free water. To avoid degradation of RNA during size fraction, cDNA and dsDNA was synthesized, before size fraction. Five microliters of RNA was used for cDNA synthesis with a random hexamer using the SuperScript III kit (Invitrogen, Carlsbad, CA, USA). To generate second-strand cDNA, single round priming and extension were performed using the Klenow fragment (New England Biolabs, Ipswich, MA, USA) with a random hexamer. Twenty microliters of cDNA was heated at $95^{\circ} \mathrm{C}$ for $2 \mathrm{~min}$ and then cooled to $4^{\circ} \mathrm{C}$ in the presence of $150 \mathrm{ng}$ of a random hexamer in $1 \times$ Klenow reaction buffer. Five units of the Klenow fragment were added to the reaction mixture and incubated at $37^{\circ} \mathrm{C}$ for $1 \mathrm{~h}$. Then, resultant dsDNA was electrophoresed on $0.6 \%$ agarose gels. Each fraction on the agarose gel [fragments 1-8 are FX, where $X=1-8$ included $X$ until $(X+1) \mathrm{kbp}$ in length] was excised as shown in Figure 1. DNA was then extracted from each fraction using NucleoSpin extract II (Machrey-Nagel, Germany), and eluted in $20 \mu \mathrm{l}$ of distilled water. PCR was performed using FCV or $28 \mathrm{~S}$ rRNA primer sets (Figure 2). We used PCR primers for amplification of a 281-bp nucleotide sequence of the FCV RNA-dependent RNA polymerase gene (FCV-F primer: 5'-AAGGATGATCTGGGGTTGTG-3', corresponding to positions 120 to 139 nt and FCV-R primer: 5'-GAATCAACAATGGGAGACCG-3', corresponding to positions 401 to 382 nt of GenBank accession number D90357) and a 477-bp fragment of human 28S rRNA (28S-F primer: 5'-CCCAGAAAAGGTGTTGGTTG-3', corresponding to positions 1936 to $1955 \mathrm{nt}$ and $28 \mathrm{~S}-\mathrm{R}$ primer: 5'-ATGGAACCCTTCTCCACTTC-3', corresponding to positions 2413 to 2394 nt of GenBank accession number NR_003287). One microliter extracted DNA after size fraction was added to the PCR reaction mixtures containing $15 \mu \mathrm{l}$ of $2 \times$ GoTaq master mix (Promega, Madison, WI, USA), forward and reverse primers (each at a concentration of $1 \mathrm{M}$ ), and distilled water to a final volume of 30 $\mu \mathrm{l}$. The thermal program consisted of $2 \mathrm{~min}$ at $94^{\circ} \mathrm{C}$, followed by 35 cycles of denaturation for $20 \mathrm{~s}$ at $94^{\circ} \mathrm{C}, 30 \mathrm{~s}$ of annealing at $50^{\circ} \mathrm{C}, 30$ $\mathrm{s}$ of elongation at $68^{\circ} \mathrm{C}$ and a final elongation step of $1 \mathrm{~min}$ at $72^{\circ} \mathrm{C}$. The main population of cellular RNA was ribosomal RNA (18s and 28s rRNA), which occupied over $95 \%$ of the RNA population. The large

${ }^{*}$ Corresponding author: T. Mizutani, Department of Virology 1, National Institute of Infectious Diseases, Gakuen 4-7-1, Musashimurayama, Tokyo, Japan, Tel: +8142-561-0771; Fax: +81-42-565-3315; E-mail: tmizutan@nih.go.jp

Accepted September 28, 2010; Published September 30, 2010

Citation: Watanabe S, Mizutani T, Sakai K, lizuka I, Shiota T, et al. (2010) Development of a Method to Detect Viral RNA Sequences From Cultured Cells by Combining Size Fraction and a Rapid Determination System for Viral RNA Sequences (RDV). J Veterinar Sci Technol 1:103. doi:10.4172/2157-7579.1000103

Copyright: () 2010 Watanabe S, et al. This is an open-access article distributed under the terms of the Creative Commons Attribution License, which permits unrestricted use, distribution, and reproduction in any medium, provided the original author and source are credited. 
Citation: Watanabe S, Mizutani T, Sakai K, lizuka I, Shiota T, et al. (2010) Development of a Method to Detect Viral RNA Sequences From Cultured Cells by Combining Size Fraction and a Rapid Determination System for Viral RNA Sequences (RDV). J Veterinar Sci Technol 1:103. doi:10.4172/2157-7579.1000103

Page 2 of 3
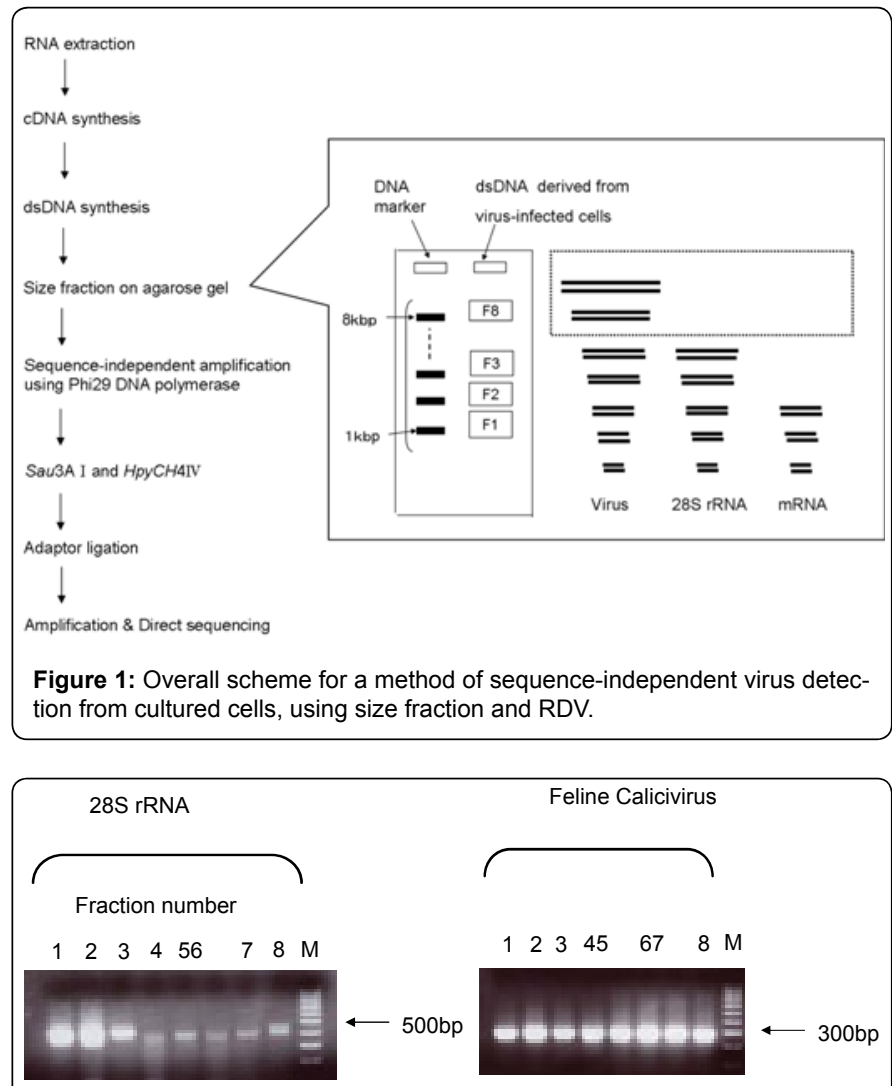

Figure 2: The result of RT-PCR on each DNA extracted from fractions of the agarose gel. The primer sets targeting $28 \mathrm{~S}$ rRNA and feline calicivirus were used for RT-PCR. M indicates 100 bp DNA ladders.

size of $28 \mathrm{~S}$ rRNA is approximately $5 \mathrm{kbp}$. Therefore, when we used a random primer for cDNA synthesis, dsDNA originating from $28 \mathrm{~S}$ rRNA was mainly detected from the fractions less than $5 \mathrm{kbp}$ (F1, F2 and F3) (Figure 2). On the other hand, FCV was observed in all fractions because the full genome size of this virus is approximately $8 \mathrm{~kb}$. It is strongly suggested that F6 to F8 contain mainly viral dsDNA and a portion of cellular dsDNA in virus-infected cells. Next, to investigate whether FCV sequences were obtained from F6 to F8 by RDV-SF, DNA extracted from F6 to F8 was mixed and subjected to ethanol precipitation. Precipitated DNA was eluted in $1 \mu \mathrm{l}$ distilled water and used for sequence-independent amplification with Phi29 DNA polymerase, which is known to favorably amplify DNA more than 3 kbp. Amplification with Phi29 DNA polymerase was performed using the GenomiPhi V2 DNA amplification kit (GE Healthcare, UK) according to the manufacturer's instructions. Amplified DNA was purified using NucleoSpin extract II and subjected to digestion with HpyCH4IV and SauBAI, and adaptor ligation, as described previously (RDV ver 3.1) [12]. For direct sequencing, 64 PCR reactions were performed using specially designed RDV primers. Each primer included an adaptor sequence and variable random nucleotides [12]. The 64 PCR products were processed by agarose gel electrophoresis. The band sizes more than $150 \mathrm{bp}$ were excised from the gel, and DNA was extracted. A total of 15 DNA fragments were sequenced by direct sequencing. Of the 15 DNA fragments, sequences of 6 fragments were not obtained. The remaining 9 DNA fragments were subjected to a BLASTN search against the DNA databank of Japan (http://www.ddbj.nig.ac.jp). Of these fragments, 2 (93-bp and 54-bp nucleotide sequences) were identical to FCV genomic RNA, and the other fragments exhibited

\begin{tabular}{|l|l|}
\hline Type of DNA fragment & No. of DNA fragment \\
\hline FCV & 2 \\
\hline Bacteriophage & 2 \\
\hline Escherichia coli & 1 \\
\hline Pseudomonas & 1 \\
\hline Unknown (due to short length) & 3 \\
\hline No read & 6 \\
\hline Total & 15 \\
\hline
\end{tabular}

Table 1: Type and number of cDNA fragments detected by RDV-SF from FCVinfected cells.

\begin{tabular}{|l|l|}
\hline Arenaviridae (segment) & $<8 \mathrm{~kb}$ \\
\hline Arteriviridae & $12-16 \mathrm{~kb}$ \\
\hline Astroviridae & $6-8 \mathrm{~kb}$ \\
\hline Bornaviridae & $9 \mathrm{~kb}$ \\
\hline Bunyaviridae (segment) & $<7 \mathrm{~kb}$ \\
\hline Caliciviridae & $7-8 \mathrm{~kb}$ \\
\hline Coronaviridae & $28-33 \mathrm{~kb}$ \\
\hline Filoviridae & $18 \mathrm{~kb}$ \\
\hline Flaviviridae & $10-12 \mathrm{~kb}$ \\
\hline Paramyxoviridae & $15-16 \mathrm{~kb}$ \\
\hline Picornaviridae & $7-8 \mathrm{~kb}$ \\
\hline Retroviridae & $7-11 \mathrm{~kb}$ \\
\hline Rhabdoviridae & $11 \mathrm{~kb}$ \\
\hline Togaviridae & $9-12 \mathrm{~kb}$ \\
\hline Birnaviridae (segment) & $<4 \mathrm{kbp}$ \\
\hline Orthomyxoviridae (segment) & $<3 \mathrm{~kb}$ \\
\hline Reoviridae (segment) & $<4 \mathrm{kbp}$ \\
\hline
\end{tabular}

Table 2: Genome (segment) length of virus family.

\begin{tabular}{|l|l|}
\hline Type of DNA fragment & No. of DNA fragment \\
\hline YOKV & 1 \\
\hline Bacteriophage & 4 \\
\hline Escherichia coli & 1 \\
\hline Pseudomonas & 1 \\
\hline Unknown (due to short length) & 1 \\
\hline No read & 5 \\
\hline Total & 13 \\
\hline
\end{tabular}

Table 3: Type and number of cDNA fragments detected by RDV-SF from YOKV-infected cells

high degrees of homology to the nucleic acid sequence of Escherichia coli, bacteriophages, or Pseudomonas (Table 1).

As shown in Table 2, most of the mammalian RNA viruses, except Birnaviridae, Orthomyxoviridae and Reoviridae, have more than $5 \mathrm{kbp}$ RNA genomes. Next, RDV-SF was also applied to the RNA extracted from Yokose virus (YOKV)-infected Vero cells. The YOKV belongs to Flaviridae, which is approximately $10 \mathrm{~kb}$ of genome length. The Oita-36 strain of YOKV was kindly provided by Dr. Tomohiko Takasaki (National Institute of Infectious Diseases of Japan). YOKV was inoculated in Vero E6 cells at a multiplicity of $1 \mathrm{TCID}_{50} /$ cell. At 2 days post infection, virus-infected cells were harvested, then RNA was extracted for applying to RDV-SF. As a result of RDV-SF, 13 DNA fragments were sequenced by direct sequencing, and 8 read fragment sequences were obtained. BLASTN showed that a 44-bp DNA fragment was identical to the YOKV genome (Table 3). Based on the result using YOKV-infected cells, the sensitivity of RDV-SF was demonstrated to be equal to that of RDV, with a culture supernatant as starting material (estimated 10,000 copies; data not shown).

In the present study, we added a size fraction step before the RDV method and developed RDV-SF for detecting RNA viral genome sequences from virus-infected cells. We demonstrated that RDV-SF could determine the nucleotide fragment sequences of both FCV and YOKV cDNA from virus-infected cells. Cellular RNA was not detected by RDV-SF. These results indicate that size fraction and subsequent 
Citation: Watanabe S, Mizutani T, Sakai K, lizuka I, Shiota T, et al. (2010) Development of a Method to Detect Viral RNA Sequences From Cultured Cells by Combining Size Fraction and a Rapid Determination System for Viral RNA Sequences (RDV). J Veterinar Sci Technol 1:103. doi:10.4172/2157-7579.1000103

Page 3 of 3

sequence-independent amplification using Phi29 DNA polymerase efficiently reduced cellular RNA and selectively enabled amplification of viral nucleotide fragment sequences. In this study, nucleotide sequences of bacteriophage, E. coli and Pseudomonas were also obtained by RDV-SF. They may have been included in the reagents used in this study. On the other hand, contamination may occur during the electrophoresis step. Although preventing contamination completely is difficult because of the high sensitivity of PCR-based amplification, it is important to treat DNA samples carefully in order to avoid contamination, particularly in the electrophoresis step of size fraction.

Combing size fraction of cDNA and RDV, we succeeded in developing a new method to efficiently detect RNA viruses from the cultured cells. RDV-SF has a potential to be a powerful diagnostic tool for detecting RNA viruses including cell-associated viruses.

\section{Acknowledgments}

We thank Ms. Momoko Ogata of the National Institute of Infectious Diseases of Japan for her assistance. This study was partly supported by a grant from the Japan Society for the Promotion of Science, the Ministry of Health, Labor and Welfare as well as the Ministry of Education, Culture, Sports, Science, and Technology, Japan.

\section{References}

1. Allander T, Emerson SU, Engle RE, Purcell RH, Bukh J (2001) A virus discovery method incorporating DNase treatment and its application to the identification of two bovine parvovirus species. Proc Natl Acad Sci U S A 98: 11609-11614.

2. Biagini $P$, Uch R, Belhouchet M, Attoui $H$, Cantaloube JF, et al. (2007) Circular genomes related to anelloviruses identified in human and animal samples by using a combined rolling-circle amplification/sequence-independent single primer amplification approach. J Gen Virol 88: 2696-2701.
3. Endoh D, Mizutani T, Kirisawa R, Maki Y, Saito H, et al. (2005) Speciesindependent detection of RNA virus by representational difference analysis using non-ribosomal hexanucleotides for reverse transcription. Nucleic Acids Res 33: e65.

4. Kihara Y, Satho T, Eshita Y, Sakai K, Kotaki A, et al. (2007) Rapid determination of viral RNA sequences in mosquitoes collected in the field. J Virol Methods 146 : 372-374.

5. Kirkland PD, Frost MJ, Finlaison DS, King KR Ridpath JF, et al. (2007) Identification of a novel virus in pigs--Bungowannah virus: a possible new species of pestivirus. Virus Res 129: 26-34.

6. Maeda K, Hondo E, Terakawa J, Kiso Y, Nakaichi N, et al. (2007) Isolation of a novel adenovirus from a fruit bat (Pteropus dasymallus yayeyamae). Emerg Infect Dis 14: $347-349$

7. Reyes GR, Kim JP (1991) Sequence-independent single-primer amplification (SISPA) of complex DNA populations. Mol Cell Probes 5: 473-481.

8. Sakai K, Mizutani T, Fukushi S, Saijo M, Endoh D, et al. (2007) An improved procedure for rapid determination of viral RNA sequences of avian RNA viruses. Arch Virol 152: 1763-1765.

9. Sakai K, Ueno Y, Ueda S, Yada K, Fukushi S, et al. (2009) Novel reovirus isolation from an Ostrich (Struthio camelus) in Japan. Vet Microbiol 134: 227-232.

10. Van der Hoek L, Pyrc K, Jebbink MF, Vermeulen-Oost W, Berkhout RJ, et al (2004) Identification of a new human coronavirus. Nature Medicine 10: 368-373.

11. Victoria JG, Kapoor A, Dupuis K, Schnurr DP, Delwart EL, et al. (2008) Rapid identification of known and new RNA viruses from animal tissues. PLoS Pathog 4: e1000163.

12. Watanabe S, Maeda K, Suzuki K, Ueda N, Iha K, et al. (2010) Nove betaherpesvirus in bats. Emerg Infect Dis 16: 986-988.

13. Yamao T, Eshita Y, Kihara Y, Satho T, Kuroda M, et al. (2009) Novel virus discovery in field-collected mosquito larvae using an improved system for rapid determination of viral RNA sequences (RDV ver4.0). Arch Virol 154: 153-158. 